\title{
A model for predicting gestational diabetes mellitus in early pregnancy: a prospective study in Thailand
}

\author{
Sattamat Lappharat, PhD ${ }^{1,2}$, Penkae Rothmanee, MD ${ }^{3}$, Kasemsak Jandee, MPH ${ }^{1,4}$, Manaphat Suksai, MD ${ }^{5}$, \\ Tippawan Liabsuetrakul, MD, PhD ${ }^{1,5}$

\begin{abstract}
${ }^{1}$ Department of Epidemiology, Faculty of Medicine, Prince of Songkla University, Songkhla; ${ }^{2}$ Department of Research and International Relations, Sirindhorn College of Public Health, Yala; ${ }^{3}$ Obstetrics and Gynecology Division, Naradhiwas Rajanagarindra Hospital, Narathiwat; ${ }^{4}$ Department of Community Public Health, School of Public Health, Walailak University, Nakhon Si Thammarat; ${ }^{5}$ Department of Obstetrics and Gynecology, Faculty of Medicine, Prince of Songkla University, Songkhla, Thailand
\end{abstract}

\section{Objective}

To develop a predictive model using the risk factors of gestational diabetes mellitus (GDM) and construct a predictive nomogram for GDM risk in women during early pregnancy.

\section{Methods}

A prospective study was conducted in two tertiary hospitals among pregnant women with gestational age $\leq 14$ weeks. Early GDM was diagnosed if an abnormal $100 \mathrm{~g}$ oral glucose tolerance test was detected using the Carpenter and Coustan criteria after an abnormal $50 \mathrm{~g}$ glucose challenge test. The factors included in the model were ACOG risk factors; maternal age; family history of hypertensive disorder in pregnancy; family history of dyslipidemia; gravida; parity; histories of preterm birth, early fetal death, abortion, stillbirth, and low birth weight; and glycated hemoglobin (HbA1c) levels. The predictive models for early GDM were analyzed using multiple logistic regression analyses. The nomograms were constructed, and their discrimination ability and predictive accuracy were tested.

\section{Results}

Of the 553 pregnant women, 54 (9.8\%) were diagnosed with early GDM. In the integrated model, there was a history of GDM (adjusted odds ratio [aOR], 5.15; 95\% confidence interval $[\mathrm{Cl}], 1.82-14.63 ; P=0.004), \mathrm{HbA} 1 \mathrm{c}$ threshold $\geq 5.3 \%$ (aOR, 2.61; 95\% Cl, 1.44-4.74; $P=0.002$ ), and family history of dyslipidemia (aOR, 2.68; 95\% Cl, 1.37-5.21; $P=0.005$ ). The integrated nomogram model showed that a history of GDM had a high impact on the risk of early GDM. Its discrimination and mean absolute error were 0.76 and 0.009 , respectively.

\section{Conclusion}

Application of the predictive model and nomogram will help healthcare providers investigate the probability of early GDM, especially in resource-limited countries.

Keywords: Diabetes, gestational; Pregnancy trimester, first; Nomograms; Diagnostic screening programs

\section{Introduction}

Gestational diabetes mellitus (GDM), described as glucose intolerance with first recognition during pregnancy, is one of the most common disorders found in pregnant women [1,2]. Although GDM is treatable, maternal and perinatal complications have been widely reported $[3,4]$. Screening and diagnosis of GDM is commonly performed at 24-28 weeks of gestation via universal screening or other strategies [5]. A systematic review that analyzed results from 11 studies in seven countries and examined the burden of GDM reported
Received: 2021.07.24. Revised: 2021.09.27. Accepted: 2021.12.08. Corresponding author: Tippawan Liabsuetrakul, MD, PhD Department of Epidemiology, Faculty of Medicine, Prince of Songkla University, 15 Kanchanavanit Road, Kho Hong, Songkhla 90110, Thailand

E-mail: ltippawa@yahoo.com

https://orcid.org/0000-0001-7687-5629

Articles published in Obstet Gynecol Sci are open-access, distributed under the terms of the Creative Commons Attribution Non-Commercial License (http://creativecommons. org/licenses/by-nc/3.0/) which permits unrestricted non-commercial use, distribution, and reproduction in any medium, provided the original work is properly cited.

Copyright $\odot 2022$ Korean Society of Obstetrics and Gynecology 


\section{Obstetrics \& Gynecology Science}

that the combined prevalence of GDM screened in the second or third trimester was $10.1 \%$ [6]. However, another systematic review reported that the prevalence of GDM in early pregnancy varied from $0.8 \%$ to $22.9 \%$. This raises the concern of undiagnosed type 2 diabetes mellitus (T2DM) before pregnancy $[7,8]$

Early screening is the key to assure early detection and effective treatment, resulting in lower consequences for both the mother and the baby [3]. However, there is currently a lack of consensus regarding the screening for GDM in early pregnancy. The United States Preventive Services Task Force Recommendation Statement recommended insufficient evidence to support the benefit or harm of screening GDM before 24 weeks in all pregnant women [9]. Moreover, universal screening and laboratory tests result in a great burden on healthcare budgets, out-of-pocket payments in the context of no health insurance, and poor infrastructure, particularly in low- and middle-income countries [10]. Therefore, a predictive model for screening for the risk of GDM at the first antenatal visit for early detection of GDM is needed.

Glycated hemoglobin (HbA1c) levels have been used to monitor and diagnose diabetes in non-pregnant individuals due to its ability to indicate average plasma glucose over a previous three-month period $[1,11]$. HbA1c level has been proposed as a potential indicator for GDM screening or to ascertain undiagnosed T2DM in early pregnancy. However, cut-off thresholds have not been determined because they depend on the study population, and they are not part of routine antenatal care $[4,12]$.

Previous studies have proposed risk-scoring systems or models using their risk factors for predicting GDM [13-15], and the American College of Obstetricians and Gynecologists (ACOG) 2018 recently updated the risk factors for women at risk of pre-gestational diabetes or early GDM [4]. The idea of integrating the risk factors from the ACOG with the riskscoring concept seems to be challenging for the implementation of a predictive model in resource-limited countries. Therefore, this study aimed to create a predictive model using the risk factors of GDM and construct a nomogram to predict the probability of GDM risk in women during early pregnancy.

\section{Materials and methods}

A prospective study was conducted in two tertiary hospitals: Songklanagarind Hospital, a university hospital, and Naradhiwas Rajanagarindra Hospital, a tertiary hospital, in Southern Thailand. All pregnant Thai women with gestational age of $\leq 14$ weeks, who attended antenatal care at these study hospitals during March 14, 2018 and March 13, 2020, were included. Those who had known medical conditions (such as diabetes mellitus, anemia, or mental illness) and incomplete test results were excluded from the analysis. The sample size was calculated based on the estimated sensitivity of the risk model at $87 \%$ [13], with an acceptable error of $10 \%$, a $95 \%$ confidence interval $(\mathrm{Cl})$, and a $9 \%$ expected prevalence of early GDM [16]. At least 484 pregnant women were screened to achieve an estimated 44 women with early GDM.

The main outcome measure of this study was the prediction of early GDM, defined as diagnosis of GDM at a gestational age of $\leq 14$ weeks via a universal 2-step approach using a $50 \mathrm{~g}$ glucose challenge test (GCT) followed by a 100 $\mathrm{g}$ oral glucose tolerance test (OGTT) [4]. Women who had a positive $50 \mathrm{~g} \mathrm{GCT}$ (1-hour plasma glucose level $\geq 140 \mathrm{mg} / \mathrm{dL}$ ) underwent a diagnostic $100 \mathrm{~g}$ OGTT after an overnight fast. GDM was diagnosed when at least two of four plasma glucose values of the $100 \mathrm{~g}$ OGTT met the Carpenter and Coustan criteria as follows: fasting plasma glucose $\geq 95 \mathrm{mg} / \mathrm{dL}$, 1-hour plasma glucose $\geq 180 \mathrm{mg} / \mathrm{dL}$, 2-hour plasma glucose $\geq 155 \mathrm{mg} / \mathrm{dL}$, and 3-hours plasma glucose $\geq 140 \mathrm{mg} / \mathrm{dL}$ [17].

The independent variables used to construct the predictive model included maternal age, family history of hypertensive disorder in pregnancy (HDP), family history of dyslipidemia (DLP), gravida, parity, history of preterm birth, history of early fetal death ( $<20$ weeks), history of abortion, history of stillbirth (fetal death $\geq 20$ weeks and neonatal death), or history of low birth weight. Additionally, selective ACOG risk factors for early GDM included pre-pregnancy body mass index (BMI), physical activity, family history of diabetes mellitus (DM), history of GDM, history of macrosomia, hypertension, and $\mathrm{HbA1c}$ levels. Pre-pregnancy BMI was calculated by dividing the pre-pregnancy weight $(\mathrm{kg})$ by the height squared $\left(\mathrm{m}^{2}\right)$ and categorized into BMl $<25$ versus $\geq 25 \mathrm{~kg} / \mathrm{m}^{2}$. Physical activity, involving activity at work, travel to and from places, and recreational activities in the previous week, were measured using the Global Physical Activity Guidelines [18,19]. 


\section{Obstetrics \& Gynecology Science}

Vol. 65, No. 2, 2022

A family history of DM, HDP, and DLP in this study were defined as a history of diseases in the mother, father, and/or sibling.

All pregnant women who visited the antenatal care unit at the study hospitals and met the inclusion and exclusion criteria were recruited. After obtaining written consent, faceto-face interviews were conducted to obtain their personal information and obstetric history. Blood samples were collected to determine 1-hour plasma glucose levels after $50 \mathrm{~g}$ GCT and HbA1c levels. All blood samples were kept in cold storage before being delivered to the clinical chemistry laboratory unit (Songklanagarind Hospital, Prince of Songkla University, Songkhla, Thailand). Glucose levels were measured using a Cobas 8,000 modular analyzer series (Roche Diagnostics $\mathrm{GmbH}$, Mannheim, Germany) using the hexokinase method. HbA1c levels (\%) were determined using a Capillarys 3 Tera (Sebia, Lisses, France) via the capillary electrophoresis technique.

Data were entered in Epidata version 3.1 (The EpiData
Association, Odense, Denmark, 2004) and analyzed using the R statistical software version 3.6.3 (The R Foundation for Statistical Computing, Vienna, Austria, 2020). Differences in descriptive information between groups were analyzed using the chi-square test or Fisher's exact test for categorical variables, and an independent $t$-test for continuous variables. The ACOG uses a HbA1c cut-off threshold of 5.7\% (39 mmol/mL); however, the optimal HbA1c threshold was calculated in this study using the "OptimalCutpoints" package, regarding the maximum product of specificity and sensitivity method [20].

The integrated model using the risk factors from the ACOG and additional risk factors was determined by multiple logistic regression analysis. Factors associated with early GDM, with a $P$-value $<0.2$ in univariate analysis, were initially used for the first model of multiple logistic regression analysis. A backward-stepwise method was then used to keep the final model with significant factors ( $P$-value $<0.05)$. The best receiver operating characteristic curve was considered to select the factors for placement into the predictive models for

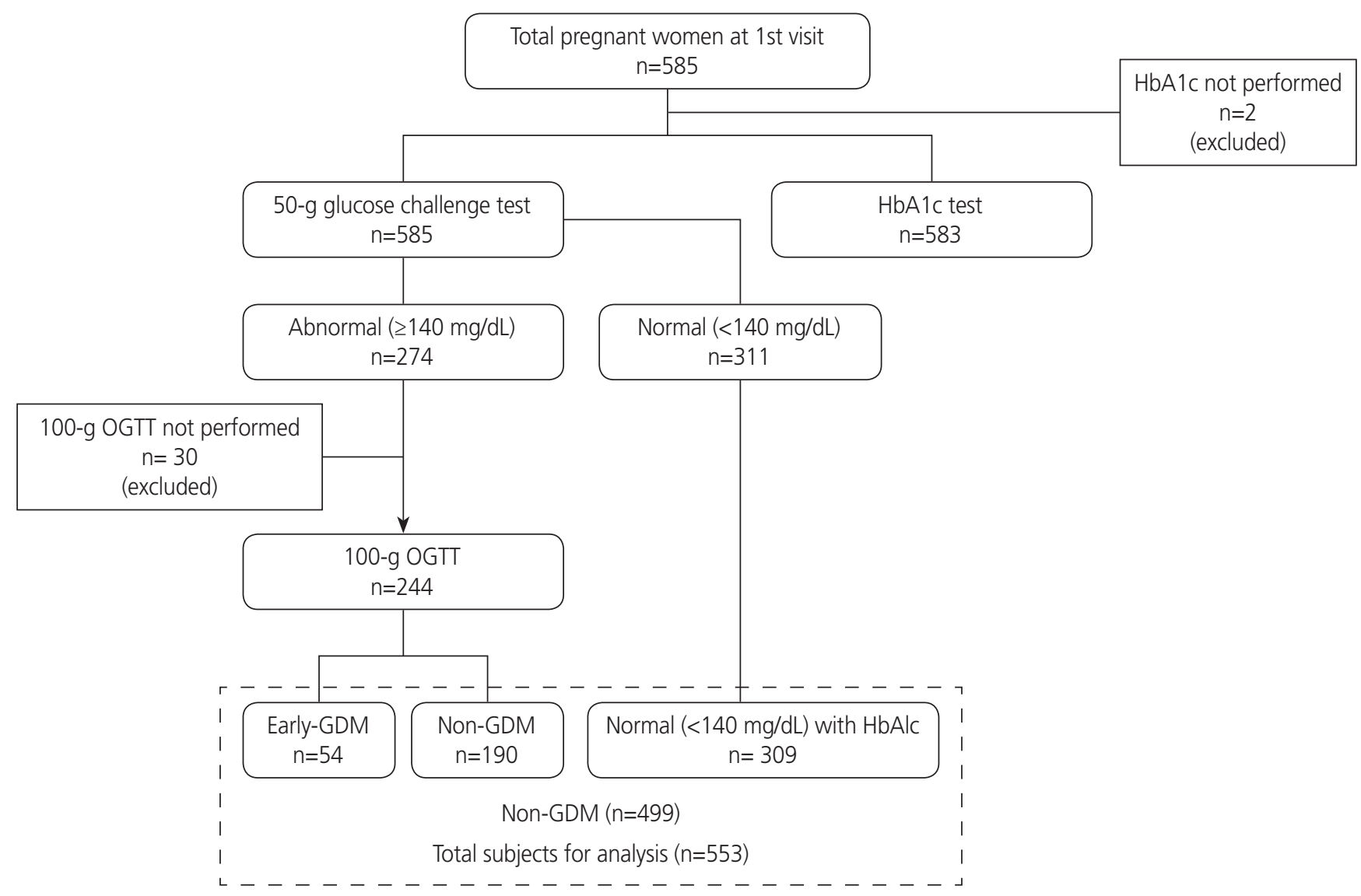

Fig. 1. Flow chart of the study. HbA1c, glycated hemoglobin; OGTT, oral glucose tolerance test; GDM, gestational diabetes mellitus. 


\section{Obstetrics \& Gynecology Science}

Sattamat Lappharat, et al. Predicting gestational diabetes mellitus

early GDM, in addition to their significance. The nomogram and calibration curve of the prediction were constructed using the regression modeling strategies (rms) in the "rms" package, which includes the functions for regression models. A bootstrapping approach with 1,000 resamples was performed to internally validate the nomogram to achieve a degree of optimism with the model $[21,22]$. The calibration curve and the Harrell concordance index (C-index) were applied to determine its predictive accuracy and discriminatory ability. A C-index $>0.5$ indicated a high prediction ability.

\section{Results}

A total of 585 pregnant women attending their first prenatal visit were included in the study. The median gestational age was eight weeks (interquartile range, 6.0-10.0). Thirtytwo were excluded from the analysis due to the lack of 100 g OGTT $(n=30)$ and HbA1c $(n=2)$ results. Of the 553 women analyzed, early GDM was found in 54 women (9.8\%). Of 244 women who underwent $100 \mathrm{~g}$ OGTT, fasting plasma glucose ranged from 61 to $120 \mathrm{mg} / \mathrm{dL}$. The flow diagram of the study is shown in Fig. 1. The personal information and obstetric history of women without GDM and early GDM are presented in Table 1. Maternal age, family history of DLP, history of early fetal death, history of preterm birth, and history of low birth weight were significantly different between the groups.

Risk factors for early GDM, selected from the ACOG recommendations between women with and without early GDM are shown in Table 2. Pregnant women with early GDM were more likely to have a pre-pregnancy BMI $\geq 25 \mathrm{~kg} / \mathrm{m}^{2}$, low inactive physical activity, family history of $\mathrm{DM}$, history of GDM, and HbA1c level over the cut-off threshold compared to those without GDM. The optimal cut-point analysis presented $5.3 \%$ as the best cut-off threshold for HbA1c, showing the area under the curve (AUC) at $0.67(95 \% \mathrm{Cl}, 0.58$ 0.75). Of the 54 women with early GDM, $24.1 \%$ and $55.6 \%$ had an $\mathrm{HbA} 1 \mathrm{c}$ threshold of $\geq 5.7 \%$ and $\geq 5.3 \%$, respectively.

The final models of risk factors associated with early GDM for the selective ACOG and integrated models are presented in Table 3. In the selective ACOG model, the odds of detect-

Table 1. Personal and obstetric information

\begin{tabular}{|c|c|c|c|c|}
\hline Variable & Total $(n=553)$ & Non-GDM $(n=499)$ & Early-GDM $(n=54)$ & $P$-value \\
\hline \multicolumn{5}{|l|}{ Personal information } \\
\hline Maternal age (yr) & $31(27.0-35.0)$ & $31(27.0-35.0)$ & $33(30.0-37.0)$ & 0.010 \\
\hline \multicolumn{5}{|l|}{ Family history } \\
\hline HDP & $9(1.6)$ & $7(1.4)$ & $2(3.7)$ & 0.216 \\
\hline DLP & $98(17.7)$ & $80(16.0)$ & $18(33.3)$ & 0.003 \\
\hline \multicolumn{5}{|l|}{ Obstetric history } \\
\hline Gravida & & & & 0.149 \\
\hline Primigravida & $198(35.8)$ & $184(36.9)$ & $14(25.9)$ & \\
\hline Multigravida & $355(64.2)$ & $315(63.1)$ & $40(74.1)$ & \\
\hline Parity & & & & 0.152 \\
\hline Nulliparous & $261(47.2)$ & $241(48.3)$ & $20(37.0)$ & \\
\hline Multiparous & $292(52.8)$ & $258(51.7)$ & $34(63.0)$ & \\
\hline \multicolumn{5}{|l|}{ History } \\
\hline Abortion & $113(20.4)$ & $104(20.8)$ & $9(16.7)$ & 0.586 \\
\hline Early fetal death & $4(0.7)$ & $2(0.4)$ & $2(3.7)$ & 0.049 \\
\hline Stillbirth & $2(0.4)$ & $1(0.2)$ & $1(1.9)$ & 0.186 \\
\hline Preterm birth & $44(8.0)$ & $35(7.0)$ & $9(16.7)$ & 0.028 \\
\hline Low birth weight & $32(5.8)$ & $25(5.0)$ & $7(13.0)$ & 0.028 \\
\hline
\end{tabular}

Values are presented as median (interquartile range) or number (\%).

GDM, gestational diabetes mellitus; HDP, hypertensive disorder in pregnancy; DLP, dyslipidemia. 


\section{Obstetrics \& Gynecology Science}

Vol. 65, No. 2, 2022

ing early GDM significantly increased in women with a history of GDM (adjusted odds ratio [aOR], $4.32 ; 95 \% \mathrm{Cl}$, 1.5212.27; $P=0.010$ ) and $\mathrm{HbA} 1 \mathrm{c}$ threshold $\geq 5.7 \%$ (aOR, 5.59; $95 \% \mathrm{Cl}, 2.36-13.23 ; P<0.001)$. In the integrated model, history of GDM (aOR, 5.15; 95\% Cl, 1.82-14.63; $P=0.004)$, $\mathrm{HbA} 1 \mathrm{c}$ threshold $\geq 5.3 \%$ (aOR, 2.61; 95\% Cl, 1.44-4.74; $P=0.002)$, and family history of DLP (aOR, $2.68 ; 95 \% \mathrm{Cl}$, $1.37-5.21, P=0.005)$ significantly increased the odds of hav-

Table 2. Selective ACOG risk factors for early GDM

\begin{tabular}{|c|c|c|c|c|}
\hline GDM risk factor & Total $(n=553)$ & Non-GDM $(n=499)$ & Early-GDM $(n=54)$ & $P$-value \\
\hline Pre-pregnancy BMI (kg/m²) & & & & 0.034 \\
\hline$<25.0$ & $373(67.5)$ & $344(68.9)$ & $29(53.7)$ & \\
\hline$\geq 25.0$ & $180(32.5)$ & $155(31.1)$ & $25(46.3)$ & \\
\hline Physical activity (MET-minutes/week) & & & & 0.045 \\
\hline Inactivity & $450(81.4)$ & $412(82.6)$ & $38(70.4)$ & \\
\hline Activity & $103(18.6)$ & $87(17.4)$ & $16(29.6)$ & \\
\hline Family history of DM & $146(26.4)$ & $122(24.4)$ & $24(44.4)$ & 0.003 \\
\hline History of GDM & $20(3.6)$ & $12(2.4)$ & $8(14.8)$ & $<0.001$ \\
\hline History of macrosomia & $11(2.0)$ & $10(2.0)$ & $1(1.9)$ & 1.000 \\
\hline Known Hypertension & $6(1.1)$ & $5(1.0)$ & $1(1.9)$ & 0.462 \\
\hline HbA1c by ACOG cut-off threshold & & & & $<0.001$ \\
\hline$<5.7(39 \mathrm{mmol} / \mathrm{mol})$ & $522(96.4)$ & $481(96.4)$ & $41(75.9)$ & \\
\hline$\geq 5.7(39 \mathrm{mmol} / \mathrm{mol})$ & $31(5.6)$ & $18(3.6)$ & $13(24.1)$ & \\
\hline $\mathrm{HbA} 1 \mathrm{c}$ by best cut-off threshold & & & & $<0.001$ \\
\hline$<5.3(34 \mathrm{mmol} / \mathrm{mol})$ & $370(66.9)$ & $346(69.3)$ & $24(44.4)$ & \\
\hline$\geq 5.3(34 \mathrm{mmol} / \mathrm{mol})$ & $183(33.1)$ & $153(30.7)$ & $30(55.6)$ & \\
\hline
\end{tabular}

Values are presented as number (\%).

ACOG, The American College of Obstetricians and Gynecologists; GDM, gestational diabetes mellitus; BMI, body mass index; MET, metabolic equivalent of task; DM, diabetes mellitus; HbA1c, glycated hemoglobin.

Table 3. Multivariate analysis of risk factors in association with early-GDM

\begin{tabular}{|c|c|c|c|c|}
\hline \multirow{2}{*}{ Determinant } & \multicolumn{2}{|c|}{ Selective ACOG model } & \multicolumn{2}{|c|}{ Integrated model } \\
\hline & aOR $(95 \% \mathrm{Cl})$ & $P$-value & aOR $(95 \% \mathrm{Cl})$ & $P$-value \\
\hline $\begin{array}{l}\text { Pre-pregnancy BMl group } \\
\left(\geq 25.0 \mathrm{~kg} / \mathrm{m}^{2} \text { vs. }<25.0 \mathrm{~kg} / \mathrm{m}^{2}\right)\end{array}$ & $1.43(0.77-2.67)$ & 0.264 & & \\
\hline Physical activity (inactive vs. active) & $0.56(0.29-1.10)$ & 0.104 & $0.56(0.28-1.09)$ & 0.099 \\
\hline Family history of DM (yes vs. no) & $1.84(0.99-3.43)$ & 0.060 & $1.74(0.93-3.25)$ & 0.086 \\
\hline History of GDM (yes vs. no) & $4.32(1.52-12.27)$ & 0.010 & $5.15(1.82-14.63)$ & 0.004 \\
\hline History of macrosomia (yes vs. no) & $0.31(0.02-4.51)$ & 0.346 & - & \\
\hline Known hypertension (yes vs. no) & $1.03(0.10-10.88)$ & 0.979 & - & \\
\hline HbA1c group ( $\geq 5.7 \%$ vs. $<5.7 \%$ ) & $5.59(2.36-13.23)$ & $<0.001$ & - & \\
\hline HbA1c group ( $\geq 5.3 \%$ vs. $<5.3 \%$ ) & - & & $2.61(1.44-4.74)$ & 0.002 \\
\hline Family history of DLP (yes vs. no) & - & & $2.68(1.37-5.21)$ & 0.005 \\
\hline History of preterm birth (yes vs. no) & - & & $2.01(0.83-4.88)$ & 0.140 \\
\hline AUC & 0.70 & & 0.76 & \\
\hline
\end{tabular}

GDM, gestational diabetes mellitus; ACOG; The American College of Obstetricians and Gynecologists; aOR, adjusted odds ratio; Cl, confidence interval; BMl; body mass index; DM, diabetes mellitus; HbA1C, glycated hemoglobin; DLP, dyslipidemia; AUC, area under curve. 


\section{Obstetrics \& Gynecology Science}

Sattamat Lappharat, et al. Predicting gestational diabetes mellitus

ing early GDM.

The factors for the integrated model showing the best AUC prediction of early GDM were history of GDM, HbA1c threshold $35.3 \%$, family history of DLP, family history of DM, physical inactivity, and history of preterm birth, as shown in the nomogram constructed (Fig. 2A). A history of GDM was found to have the highest impact on the prediction of early GDM. The discrimination of the nomogram yielded a c-index of $0.76(95 \% \mathrm{Cl}, 0.75-0.76)$. The mean absolute error of the calibration curve of the nomogram was 0.009 (Fig. 2B).

\section{Discussion}

GDM in early pregnancy was found in 1 of 10 pregnant women in Southern Thailand. The history of GDM and $\mathrm{HbA1c}$ levels significantly remained in the model using the selective ACOG factors for predicting early GDM, whereas history of GDM, HbA1c levels, and family history of DLP did so in the integrated model. A visual nomogram, constructed using family and obstetric history, physical activity and $\mathrm{HbA} 1 \mathrm{c}$ in the integrated model, is applicable to increase the probability of early GDM detection during GDM screening in rou-

A

Points

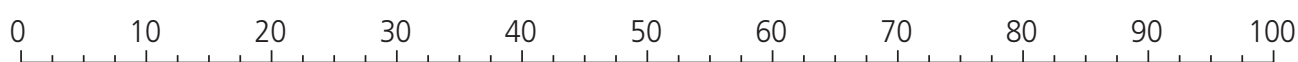

Family history of DLP

$$
\text { No }(\text { score }=0)
$$

Yes (score $=60)$

History of preterm birth

No (score $=0)$

Physical activity

Family history of DM

Active $($ score $=0) \quad$ Yes (score $=33.8)$

No (score $=0$ )

Yes $($ score $=100)$

History of GDM

$\mathrm{HbA1C}$

$$
\text { No (score=0) }
$$

$\geq 5.3$ (score $=58.5)$

$<5.3$ (score $=0)$

Total points

Probability early-GDM

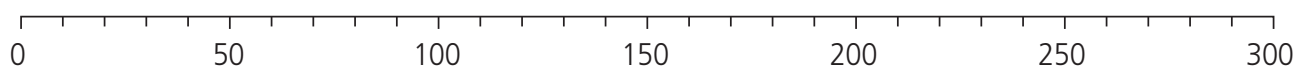

Probability early-GDM

$0.05 \quad 0.1$

0.2

0.3

$\begin{array}{llll}0.4 & 0.5 & 0.6 & 0.7\end{array}$

0.8

B

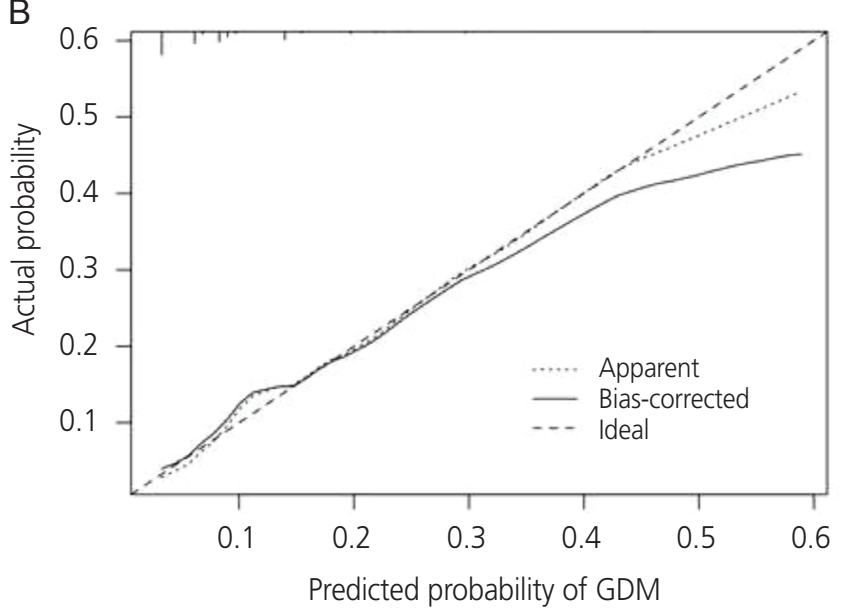

$B=1,000$ repetitions, boot
Mean absolute error $=0.009, n=533$
Fig. 2. Nomogram and calibration curve of the integrated model: (A) nomogram and (B) calibration plot. DLP, dyslipidemia; DM, diabetes mellitus; GDM, gestational diabetes mellitus; HbA1c, glycated hemoglobin; $B$, bootstrapping. 


\section{Obstetrics \& Gynecology Science}

Vol. 65, No. 2, 2022

tine practice.

A personal and family history of GDM were found to be predictors for early GDM in this study; these results concur with those of a retrospective study in China, which was a machine learning study using the variables extracted in early pregnancy within 12 weeks of gestation [23]; however, information on gestational age, when GDM was diagnosed, was not provided [23]. This finding was of concern as it might indicate the problem of unrecognized DM in women with a history of GDM [1]. Based on several professional recommendations, women with GDM should be followed up to have a $75 \mathrm{~g}$ glucose tolerance test performed at least 6-12 weeks after delivery to diagnose glucose intolerance or DM $[24,25]$. However, women with GDM were less likely to undergo postpartum testing, as recommended [26].

$\mathrm{HbA1c}$ level was another significant risk factor in both the selective and integrated models for predicting early GDM. This finding was consistent with the results of Arbib et al. [15] in which $\mathrm{HbA1c}$ level was considered one factor to add to the predictive model to screen for GDM in early pregnancy. Although $\mathrm{HbA} 1 \mathrm{c}$ level was a strong predictor, it was not recommended for use as an individual factor to predict GDM $[27,28]$ or as an alternative test to diagnose GDM because of its variation in cut-off and diagnostic performance $[12,29]$. A family history of DLP appeared to be a significant factor associated with early GDM in the integrated model. Previous studies have also reported an association between DLP and GDM, in which they reported higher detection of dyslipidemia in women with GDM than in those without GDM $[30,31]$. However, there is no clear evidence to explain the effect of a family history of DLP on GDM.

From the literature search, five studies that presented nomograms for GDM were found. These included three studies predicting the risk of GDM [32-34], one study predicting insulin requirement [35], and another study predicting postpartum T2DM [36]. In these three previous studies for predicting the risk of GDM, they used $75 \mathrm{~g} \mathrm{OGTT} \mathrm{as} \mathrm{their} \mathrm{diagnostic}$ criteria, not $100 \mathrm{~g} \mathrm{OGTT,} \mathrm{as} \mathrm{in} \mathrm{our} \mathrm{study.} \mathrm{Additionally,} \mathrm{these}$ three studies did not predict GDM during early pregnancy. Although the nomograms were constructed by selecting all significant and non-significant factors from ACOG recommendations [4], the discriminative performance of the nomograms for predicting GDM at early pregnancy was quite similar to the findings of previous studies conducted in China and South Africa for predicting GDM at 24-28 weeks of pregnancy $[33,34]$. From a systematic review of diagnostic test accuracy studies in Southeast Asia, the prevalence of GDM screened using a two-step approach at 24-28 weeks ranged from $7.1 \%$ to $28.6 \%$ in Thailand [37]. Two retrospective studies were published in 2020 [38] and 2021 [16], which showed the rates of early onset GDM at $18.9 \%$ and $9.2 \%$, respectively. The variation in the reported early GDM rate depends on universal screening or screening in high-risk pregnant women.

This study reassures the need for assessment of glucose intolerance and DM during the postpartum period for all women with GDM [39]. Additionally, it highlights the alarming and unrecognized prevalence of DM or early GDM in lowincome and middle-income countries. The findings in this study should be considered in the context of the following limitations: first, the nomogram must be tested for its validation due to its first development. Second, prior-pregnancy factors might have influenced the higher risk scores. Third, personal information included family history that might have caused under-or over-estimation due to recall bias. Fourth, generalizability may be limited in other populations with different ethnicities or risk of diseases. Finally, the effect of GDM treatment in early pregnancy is required to be further explored as a previous study reported that the use of different diagnostic criteria influenced the incidence of macrosomia differently [40].

In conclusion, the nomogram is an easy-to-use and lowcost tool to predict the probability of early onset GDM at the first antenatal visit. Therefore, it could facilitate healthcare providers in distinguishing those who are either high- or lowrisk for GDM in early pregnancy. The health outcomes on the benefits and harms of GDM screening in early pregnancy should be further studied.

\section{Conflict of interest}

All authors report no conflicts of interest.

\section{Ethical approval}

This study was approved by the Ethics Committees of the Faculty of Medicine, Prince of Songkla University, Thailand, in accordance with the Declaration of Helsinki (REC number: 


\section{Obstetrics \& Gynecology Science}

Sattamat Lappharat, et al. Predicting gestational diabetes mellitus

60-413-18-1). All eligible pregnant women signed a consent form before participating in the study. All data were collected using codes to maintain an anonymous process and were kept confidentially.

\section{Patient consent}

All recruited pregnant women were informed and signed the consent form before participating in this study. No use of images from participants was involved, thus the consent for image use was not required for publication.

\section{Funding information}

This research was financially supported by the Thailand Science Research and Innovation (TSRI) Research Career Development Grant (RSA) (Grant Number RSA6180009) and the Targeted Research Grants Program of the Faculty of Medicine, Prince of Songkla University, Thailand. The authors declare no conflict of interest.

\section{Acknowledgments}

We thank the directors of the study hospitals for their permission to conduct the study, and the health personnel at antenatal care clinics for their support during data collection. We also acknowledge Mr. Andrew Jonathan Tait, Office of International Affairs, Faculty of Medicine, Prince of Songkla University for his help with proofreading.

\section{References}

1. American Diabetes Association. (2) Classification and diagnosis of diabetes. Diabetes Care 2015;38(Suppl 1):S8-16.

2. Buchanan TA, Xiang AH. Gestational diabetes mellitus. J Clin Invest 2005;115:485-91.

3. National Collaborating Centre for Women's and Children's Health. Diabetes in pregnancy: management of diabetes and its complications from preconception to the postnatal period [Internet]. Bethesda (MD): National Center for Biotechnology Information; c2015 [cited
2021 Feb 3]. Available from: https://www.ncbi.nlm.nih. gov/books/NBK293625/.

4. ACOG practice bulletin No. 190: gestational diabetes mellitus. Obstet Gynecol 2018;131:e49-64.

5. American Diabetes Association. 2. Classification and diagnosis of diabetes. Diabetes Care 2017;40(Suppl 1): S11-24.

6. Gyasi-Antwi P, Walker L, Moody C, Okyere S, Salt K, Anang $L$, et al. Global prevalence of gestational diabetes mellitus: a systematic review and meta-analysis. [Internet]. New York (NY): The New American Journal of Medicine; c2020 [cited 2021 Feb 3]. Available from: https:// nottingham-repository.worktribe.com/output/4766016.

7. Boriboonhirunsarn D, Sunsaneevithayakul P, Nuchangrid $\mathrm{M}$. Incidence of gestational diabetes mellitus diagnosed before 20 weeks of gestation. J Med Assoc Thai 2004;87:1017-21.

8. Immanuel J, Simmons D. Screening and treatment for early-onset gestational diabetes mellitus: a systematic review and meta-analysis. Curr Diab Rep 2017;17:115.

9. US Preventive Services Task Force, Davidson KW, Barry MJ, Mangione CM, Cabana M, Caughey AB, et al. Screening for gestational diabetes: US preventive services task force recommendation statement. JAMA 2021;326:531-8.

10. Utz B, De Brouwere V. "Why screen if we cannot followup and manage?" Challenges for gestational diabetes screening and management in low and lower-middle income countries: results of a cross-sectional survey. BMC Pregnancy Childbirth 2016;16:341.

11. American Diabetes Association. Standards of medical care in diabetes--2011. Diabetes Care 2011;34 Suppl 1 (Suppl 1):S11-61.

12. Amaefule CE, Sasitharan A, Kalra P, lliodromoti S, Huda MSB, Rogozinska $E$, et al. The accuracy of haemoglobin $A 1 c$ as a screening and diagnostic test for gestational diabetes: a systematic review and meta-analysis of test accuracy studies. Curr Opin Obstet Gynecol 2020;32:32234.

13. Phaloprakarn C, Tangjitgamol S. Risk assessment for preeclampsia in women with gestational diabetes mellitus. J Perinat Med 2009;37:617-21.

14. Savvidou M, Nelson SM, Makgoba M, Messow CM, Sat$\operatorname{tar} N$, Nicolaides K. First-trimester prediction of gestational diabetes mellitus: examining the potential of com- 


\section{Obstetrics \& Gynecology Science}

Vol. 65, No. 2, 2022

bining maternal characteristics and laboratory measures. Diabetes 2010;59:3017-22.

15. Arbib N, Shmueli A, Salman L, Krispin E, Toledano Y, Hadar E. First trimester glycosylated hemoglobin as a predictor of gestational diabetes mellitus. Int J Gynaecol Obstet 2019;145:158-63.

16. Boriboonhirunsarn D, Sunsaneevithayakul P, Pannin C, Wamuk T. Prevalence of early-onset GDM and associated risk factors in a university hospital in Thailand. J Obstet Gynaecol 2021;41:915-9.

17. Carpenter MW, Coustan DR. Criteria for screening tests for gestational diabetes. Am J Obstet Gynecol 1982; 144:768-73.

18. World Health Organization. WHO STEPS surveillance manual: the WHO STEP wise approach to chronic disease risk factor surveillance. Geneva: World Health Organization; 2005.

19. Armstrong T, Bull F. Development of the World Health Organization global physical activity questionnaire (GPAQ). J Public Health 2006;14:66-70.

20. López-Ratón M, Rodríguez-Álvarez MX, Suárez CC, Sampedro FG. OptimalCutpoints: an R package for selecting optimal cutpoints in diagnostic tests. J Stat Soft 2014;61:1-36.

21. Steyerberg EW, Harrell FE Jr. Prediction models need appropriate internal, internal-external, and external validation. J Clin Epidemiol 2016;69:245-7.

22. Harrell FE Jr. rms:regression modeling strategies. R package version 6.0-0 2020 [Internet]. CRAN.R; c2020 [cited 2020 Jan 6]. Available at https://CRAN.R-project.org/ package $=$ rms.

23. Wu YT, Zhang CJ, Mol BW, Kawai A, Li C, Chen L, et al. Early prediction of gestational diabetes mellitus in the Chinese population via advanced machine learning. J Clin Endocrinol Metab 2021;106:e1191-205.

24. American Diabetes Association. 2. Classification and diagnosis of diabetes: standards of medical care in diabetes-2021. Diabetes Care 2021;44(Suppl 1):S15-33.

25. ACOG Practice Bulletin No. 190: gestational diabetes mellitus. Obstet Gynecol 2018;131:e49-64.

26. Liu ZY, Zhao JJ, Gao LL, Wang AY. Glucose screening within six months postpartum among Chinese mothers with a history of gestational diabetes mellitus: a prospective cohort study. BMC Pregnancy Childbirth 2019;19:134.
27. Fong A, Serra AE, Gabby L, Wing DA, Berkowitz $\mathrm{KM}$. Use of hemoglobin A1C as an early predictor of gestational diabetes mellitus. Am J Obstet Gynecol 2014;211:641.e1-7.

28. Osmundson SS, Zhao BS, Kunz L, Wang E, Popat R, Nimbal VC, et al. First trimester hemoglobin A1c prediction of gestational diabetes. Am J Perinatol 2016;33:977-82.

29. Siricharoenthai $P$, Phupong $V$. Diagnostic accuracy of $\mathrm{HbA1}$ c in detecting gestational diabetes mellitus. J Matern Fetal Neonatal Med 2020;33:3497-500.

30. Ryckman KK, Spracklen CN, Smith CJ, Robinson JG, Saftlas AF. Maternal lipid levels during pregnancy and gestational diabetes: a systematic review and metaanalysis. BJOG 2015;122:643-51.

31. O'Malley EG, Reynolds CME, Killalea A, O'Kelly R, Sheehan SR, Turner MJ. Maternal obesity and dyslipidemia associated with gestational diabetes mellitus (GDM). Eur J Obstet Gynecol Reprod Biol 2020;246:67-71.

32. van Leeuwen $M$, Opmeer BC, Zweers EJ, van Ballegooie $E$, ter Brugge $H G$, de Valk HW, et al. Estimating the risk of gestational diabetes mellitus: a clinical prediction model based on patient characteristics and medical history. BJOG 2010;117:69-75.

33. Adam S, Rheeder P. Selective screening strategies for gestational diabetes: a prospective cohort observational study. J Diabetes Res 2017;2017:2849346.

34. Guo F, Yang S, Zhang Y, Yang X, Zhang C, Fan J. Nomogram for prediction of gestational diabetes mellitus in urban, Chinese, pregnant women. BMC Pregnancy Childbirth 2020;20:43.

35. Souza ACRLA, Costa RA, Paganoti CF, Rodrigues AS, Zugaib $M$, Hadar $E$, et al. Can we stratify the risk for insulin need in women diagnosed early with gestational diabetes by fasting blood glucose? J Matern Fetal Neonatal Med 2019;32:2036-41.

36. Li W, Leng J, Liu H, Zhang S, Wang L, Hu G, et al. Nomograms for incident risk of post-partum type 2 diabetes in Chinese women with prior gestational diabetes mellitus. Clin Endocrinol (Oxf) 2019;90:417-24.

37. Lappharat S, Liabsuetrakul T. Accuracy of screening tests for gestational diabetes mellitus in Southeast Asia: a systematic review of diagnostic test accuracy studies. Medicine (Baltimore) 2020;99:e23161.

38. Glaharn P, Chumworathayi B, Kongwattanakul K, Sutthasri N, Wiangyot P. Proportion of abnormal second 


\section{Obstetrics \& Gynecology Science}

Sattamat Lappharat, et al. Predicting gestational diabetes mellitus

50-g glucose challenge test in gestational diabetes mellitus screening using the two-step method in high-risk pregnant women. J Obstet Gynaecol Res 2020;46:229-36.

39. Bravo-Valenzuela NJM, Peixoto AB, Mattar R, Araujo Júnior E. Fetal cardiac function by mitral and tricuspid annular plane systolic excursion using spatio-temporal image correlation M-mode and left cardiac output in fe- tuses of pregestational diabetic mothers. Obstet Gynecol Sci 2021;64:257-65.

40. Lee KH, Han YJ, Chung JH, Kim MY, Ryu HM, Kim JH, et al. Treatment of gestational diabetes diagnosed by the IADPSG criteria decreases excessive fetal growth. Obstet Gynecol Sci 2020;63:19-26. 